\title{
El estatus del concebido y la problemática de la fecundación asistida
}

\author{
Juan Morales Godo*
}

\begin{abstract}
Con poco que se reflexione en los problemas, novedosos o recurrentes, que presenta el extenso campo de la bioética, se cae en cuenta de la enorme complejidad de los mismos, tanto por lo que hace a la comprensión de los propios avances científicos como por la posibilidad de una clara conceptualización y un rigor argumentativo. A tal complejidad, y de alguna manera consecuente con ella, se añade la propia del análisis jurídico. Quizás hoy más que nunca el jurista se ve en la necesidad de echar mano de todos sus recursos teóricos y metodológicos para prever, debatir, proponer y diseñar la normatividad adecuada que le imponen los retos de la ciencia y de la ética.
\end{abstract}

Rodolfo Vásquez ${ }^{1}$

\section{Ciencia, ética y derecho: a propósito de la inseminación artificial y la fecundación extrauterina}

Uno de los hechos más notables ocurridos dentro del campo de la biología, en los últimos treinta años, es el relacionado con la posibilidad de generar vida humana fuera del útero femenino, esto es, la denominada fecundación extrauterina o fecundación in vitro; sin embargo, tampoco se puede dejar de mencionar las técnicas de inseminación artificial que facilitan la procreación intrauterina. La manipulación de los elementos que originan la vida es un avance cualitativo de gran trascendencia, porque permite dar solución a determinados problemas que impiden que la concepción se produzca de una manera natural, esto es, por medio de una relación sexual entre un hombre y

Profesor ordinario de la Pontificia Universidad Católica del Perú.

VÁSQUEZ, Rodolfo. Bioética y Derecho. México D. F.: Fondo de Cultura Económica, 1999. 
una mujer. No se trata de una mera acumulación de conocimientos, sino que se trata de conocimientos revolucionarios, de aquellos que, juntamente con otros, provocan los saltos históricos, el inicio de nuevas eras. ${ }^{2}$

Sin embargo, aun reconociendo los grandes beneficios que están procurando para la humanidad estos avances de la ciencia, existe una serie de cuestionamientos de orden ético, especialmente por parte de la Iglesia católica, que es necesario afrontar para alcanzar niveles de consenso aceptables, para luego entrar en el examen de los distintos problemas de orden jurídico que ello genera. Lo jurídico no puede ser ajeno al avance de la ciencia, pero tampoco puede prescindir de los aspectos valorativos. Diríamos que la ciencia y lo ético son los presupuestos básicos, ya que, sin haber tomado determinaciones sobre estos aspectos, no existiría el sustento jurídico adecuado frente a la sociedad. Lo jurídico debe ser consecuencia de haberse logrado niveles de consenso social sobre estos temas. ${ }^{3}$

Asimismo, no deja de ser una preocupación la posibilidad del manejo irresponsable de los elementos que originan la vida, de tal forma que se pudiera poner en peligro la naturaleza misma del ser humano. En efecto, el nivel de conocimiento respecto de los elementos que originan la vida ha generado las prácticas de una serie de combinaciones genéticas en el campo de la zoología y botánica, que ha creado nuevas especies, con características muy particulares, distintas de las especies aportantes. Si así ha ocurrido en dichos campos, nada nos impide pensar que ello no pueda ocurrir con la especie humana. Con esto, no solo nos referimos al tema de la selección eugenésica, de por sí reprobable, sino también a qué tipo de mutaciones podría ocurrir con el ser humano. Por ello, no es extraño que, a nivel universal, se haya determinado que la especie humana es un bien que jurídicamente debe ser protegido. ${ }^{4}$

El papel que le corresponde al jurista es trascendental, porque se con-

KUHN, Thomas. Qué son las revoluciones científicas y otros ensayos. Barcelona, Buenos Aires, México D. F.: Paidós, 1989, pp. 56-59. Citado por GONZALES MANTILLA, Gorky. La consideración jurídica del embrión in vitro. Lima: Pontificia Universidad Católica del Perú, 1996, p. 16.

3 DIEBOLB, John. El Hombre y el ordenador. Madrid: Pirámide, 1974. El referido autor señalaba lo siguiente premonitoriamente: "En el curso de las tres próximas décadas pueden surgir ante nosotros, en cualquier momento, amenazas contra la intimidad del individuo, el control del comportamiento humano y la capacidad para alterar el desarrollo genético. Las dos primeras se hallan ya muy próximas a nosotros y, en cuanto a la tercera, es posible que no se nos presente hasta finales del siglo. Pero, en gran medida, las tres pertenecen al mismo ámbito, a saber: el problema del individuo insuficientemente protegido por las instituciones sociales, las leyes y los preceptos formulados por sus predecesores, para enfrentarse a los distintos desafíos» (p. 34).

4 BERGEL, Salvador Darío. "Libertad de investigación y responsabilidad de los científicos en el campo de la genética humana». En Bioética y genética. Buenos Aires: Ciudad 
vierte en el puente entre los avances de la ciencia y la tecnología y los valores que las sociedades quieren privilegiar. Este cotejo permanente es el que deben realizar los juristas, a fin de no convertirse en una traba para el desarrollo científico. Para ello, deben tratar de entender a cabalidad las nuevas propuestas de la ciencia, pero cuidando que los valores y principios que privilegian las sociedades, $y$, en este caso, la humanidad en su conjunto, sean respetados, sobre la base de aquello que sustenta los derechos fundamentales de todo ser humano, esto es, su dignidad. ${ }^{5}$

No se debe permitir ni una regulación draconiana que inmovilice las investigaciones científicas ni una libertad absoluta sin ningún tipo de control social. En ese sentido, se deben buscar los consensos, y no la predominancia de alguna creencia o convicción de grupos determinados, que permitan encontrar los senderos del progreso sin afectar los valores sociales esenciales. Esa es la tarea, en buena cuenta, de la Bioética.

\section{Antecedentes de la inseminación artificial y la fecundación extrau- terina}

El primer antecedente conocido de fecundación extracorpórea de embriones humanos data de 1944, cuando dos biólogos, Rock y Meneen, obtuvieron cuatro embriones a partir de más de 100 ovocitos extraídos de ovarios y expuestos a espermatozoides. ${ }^{6}$

Una fecha que se debe tener presente en este tema es el 26 de julio de

Argentina, 2000. El referido autor nos dice: "Con el predominio de la ciencia de la vida - señala Kottow - la experimentación da otro salto cualitativo. Ya no sólo crea situaciones artificiales, sino verdaderos modelos experimentales, los que a su vez pasan a ser nuevos entes - bacterias clonadas, cepas de ratas cancerosas, células reproducidas in vitro, quimeras-. A más tardar ahora la investigación en ciencias biológicas ya no puede sustraerse al análisis bioético, habiendo prescindido de la observación para provocar en seres vivos cambios cuyo carácter y magnitud no son predecibles, precisamente porque están inmersos en las incógnitas que se investigan» (p. 35).

5 CASADO, María. Bioética, Derecho y Sociedad. Madrid: Trotta, 1998. La jurista española nos dice: "Generalmente suele darse por sentada la existencia de una cultura de las ciencias y otra de letras. Al mismo tiempo se pone de manifiesto que los adelantos biotecnológicos suscitan interrogantes para la humanidad de una envergadura tal que hace necesaria la superación de esta dicotomía y el establecimiento de ámbitos de reflexión pluridisciplinar. Precisamente ahí se sitúa el origen de la Bioética, una nueva disciplina que aparece como puente entre las ciencias y las humanidades. En realidad, y más que a controversias entre los dos campos del conocimiento, quizá sea más acertado referirse a la coincidencia de ambos en una preocupación conjunta por las consecuencias del veloz avance biotecnológico y en el acuerdo acerca de la necesidad de establecer controles sobre el mismo» (p. 55).

6 LOYARTE, Dolores y Adriana ROTONDA. Procreación humana artificial: un desafío bioético. Buenos Aires: Desalma, 1995, p. 118. 
1978. Ese día, en el Oldham Hospital, situado en la localidad de Oldham Mumps, cercano a la ciudad de Manchester, Gran Bretaña, nació la niña Louise Brown, concebida fuera del útero materno, mediante la fecundación in vitro de un óvulo proporcionado por la madre, Lesley Brown, quien padecía de obstrucción de las trompas de falopio, con el esperma de su esposo, John Brown. Una vez obtenida la fecundación, el embrión (huevo o cigoto) fue implantado en el útero de Lesley Brown para que culminara su etapa de desarrollo fetal. Los médicos que intervinieron en este hecho fueron los doctores Patrick Steptoe, ginecólogo, y Robert Edwards, fisiólogo. Como lo indica Zannoni: «Por primera vez — públicamente al menos - se había logrado cerrar el ciclo: la fecundación extrauterina de un ser humano, la posterior implantación del embrión en el útero y su desarrollo completo hasta alcanzar el nacimiento».?

Sin embargo, el hecho es consecuencia de un largo período de experimentación en el campo de la octogénesis y la embriología. Los primeros experimentos científicos en el campo de la reproducción humana datan de doscientos años atrás, pero es en el siglo XX y, concretamente, a partir de la década del cuarenta cuando los experimentos que se habían logrado con animales se extienden a los seres humanos con mayor frecuencia. Figuran, en la lista de los médicos que trabajaron este tema, Lamdium y Shettles (1953), Petrov (1958) y Moricard (1959).

Un hito importante ha sido el experimento realizado por el biólogo italiano Daniel Petrucci, entre los años 1960 y 1961, quien logró el desarrollo de embriones in vitro, uno de los cuales se mantuvo con vida - en el tubo de ensayo- por más de 60 días. El hecho motivó una serie de cuestionamientos, por lo que el indicado médico, a solicitud de la Iglesia católica, decidió interrumpir el experimento

El tema nos plantea —indudablemente - una serie de problemas de orden ético y jurídico, conforme lo mencionaremos al analizar tanto la inseminación artificial como la fecundación extrauterina. Pero debemos partir de algunas ideas básicas relacionadas específicamente con el concebido, para luego desembocar en el tratamiento de los distintos temas relacionados con la procreación.

\section{El concebido}

Para arribar a una definición del concebido, es preciso señalar que la doctrina se refiere al nasciturus como expresión genérica, entendido como el que habrá de nacer. Como especies de esta expresión genérica, se comprende al

ZANNONI, Eduardo. Inseminación artificial y fecundación extrauterina. Buenos Aires: Astrea, 1978, p. 20. 
conceptus o concebido y al concepturus (el que habrá de ser concebido).

En consecuencia, mientras el concebido es una realidad biológica y jurídica, el concepturus es una ficción jurídica. El concebido es el ser humano antes de su nacimiento y constituye la primera etapa de la vida humana; si bien dependiente biológicamente de la madre, forma una individualidad genética. Siendo una realidad desde el punto de vista biológico, no se entendía cómo el Código Civil de 1936 lo protegía recurriendo a la ficción de considerarlo como nacido. Por ello, el legislador de 1984 optó por brindarle un tratamiento directo, sin ficción alguna, pero respetando el concepto de persona, que es el ser humano a partir de su nacimiento con vida, y lo consideró como sujeto de derecho.

El concepturus, en cambio, es una ficción jurídica, porque en realidad no es un ser existente, sino es el que va a ser concebido. Por lo tanto, no es el concebido, que sí es una realidad. «La diferencia ontológica entre ambos es radical». ¿Cómo entender esta posibilidad jurídicamente hablando? Es indudable que el concepturus, inevitablemente, está en relación a un determinado acto jurídico, en el que se dispone algo a su favor. En nuestro sistema jurídico, no se ha regulado su existencia. No existe la posibilidad de actos de disposición en favor de alguien que aún no ha sido concebido.

\section{Inicio de la vida. ¿Desde cuándo estamos frente a un concebido?}

Tema de extraordinaria trascendencia y actualidad es el de determinar el inicio de la vida humana. ¿Desde qué momento estamos frente a un concebido, para poder protegerlo y considerarlo como sujeto de derecho? ¿Cuándo comienza la vida? Estas son preguntas de cuya respuesta dependerá la protección del sistema jurídico, y, por ende, muchos temas tendrán que ser replanteados. Por otro lado, es preciso reconocer la presión que han generado los avances de la ciencia y la tecnología, específicamente en el campo de la biología y la medicina, en los que, probablemente, con una concepción tradicional, dichos avances se verían obstaculizados. Sin embargo, de por medio se encuentra el ser humano, principio y fin del derecho, premunido de dignidad, todo lo cual determina que es un fin en sí mismo, jamás medio para nada; ni siquiera puede ser objeto de experimentación, aun cuando los propósitos puedan ser considerados loables. En estos temas, creemos que el fin no justifica los medios.

Pero el derecho debe estar atento a los avances de la ciencia y la tecnolo-

8 Fernandez Sessarego, Carlos. Nuevas tendencias en el Derecho de las Personas. Lima: Universidad de Lima, 1990, p. 71. 
gía; no puede dar la espalda a la evolución del conocimiento, pues es el encargado de generar el puente necesario entre dichos avances y los valores que la sociedad quiere privilegiar.

Existen hasta tres teorías que tratan de dar una explicación al tema del inicio de la vida humana. Sobre estas tres teorías, hace referencia Fernández Sessarego. ${ }^{9}$

\section{a) Teoría de la concepción}

Para esta teoría, la vida humana comienza con la concepción, entendida como la unión del espermatozoide masculino con el óvulo femenino, que se plasma a las pocas horas de la relación sexual. En ese sentido, cualquier determinación que se adopte después de la relación sexual podría ser considerada como un atentado contra la vida del ser humano.

Los partidarios de esta teoría señalan que los últimos descubrimientos de la biología ratifican sus postulados, en el sentido de que, penetrado el óvulo por el espermatozoide, surge una nueva vida, distinta de la madre, con un patrimonio genético único, irrepetible, autogobernado por el mismo embrión, sin que exista otro momento en su evolución como para poder postergar la certeza de que tal formación es vida humana. ${ }^{10}$

Es conveniente aclarar que la concepción no debe confundirse con la fecundación. La fecundación es el primer instante con el que se inicia el ciclo vital, que ocurre cuando el espermatozoide penetra el óvulo, por lo que la concepción vendría a ser el resultado de dicho primer momento, dentro del proceso del inicio de la vida. Sin embargo, este primer momento fecundación-concepción es tan rápido que la fecundación implica la concepción instantánea. ${ }^{11}$

Nuestro Código Civil, apoyado en la doctrina de la Iglesia católica, adopta - expresamente- esta posición al señalar, en el artículo primero, que la vida humana comienza con la concepción. Fernández Sessarego se convirtió en el principal defensor de este planteamiento, cuestionando la teoría de la anidación, a pesar de reconocer que de ser humano, genéticamente, solo se podría hablar cuando se produce su individuación, es decir, cuando adquiere las propiedades de unicidad y unidad, lo que se produce al concluir

Véase sus obras Derecho de las Personas. Lima: Studium, 1986; y Nuevas tendencias en el Derecho de las Personas. Op cit.

10 MARTINEZ, Stella Maris. Manipulación genética y Derecho Penal. Buenos Aires: Universidad, 1994, p. 77.

11 VARSI, Enrique. Derecho genético. 4. ${ }^{a}$ ed. Lima: Grijley, 2001, p. 91. 
la anidación, que ocurre a los 14 días a partir de la fecundación. Sin embargo, la distinción entre vida humana y ser humano, que propugnan los partidarios de la teoría de la anidación, que reconocen — que duda cabe- que antes de los 14 días se trataría de vida humana, pero no de un ser humano propiamente dicho, el jurista peruano la considera intrascendente, por cuanto la vida humana pertenece al ser humano y no a otro ser de distinta naturaleza. ${ }^{12}$

Luego de hacer un recorrido sobre las distintas teorías, que tratan de dar una explicación sobre el momento en que se inicia la vida, considera que «ontológicamente, por el hecho de la fecundación de un óvulo por un espermatozoide nos hallamos frente a un ser de naturaleza humana. Esta es la realidad biológica que interesa tener en cuenta para el efecto de considerar normativamente como sujeto de derecho a este nuevo ser y brindarle, en consecuencia, la protección jurídica debida». ${ }^{13}$

En Argentina, el reconocido constitucionalista Germán Bidart Campos se expresa en términos similares al señalar taxativamente que

[...] aunque se discuta la existencia de la «persona» antes del «día catorce» por la falta de certeza sobre la individualidad del sujeto, sin dudas lo que sí existe es «vida humana» (resulten uno o más sujetos en el futuro, o ninguno, pues potencialmente la vida humana igual inició su ciclo, aunque luego vea frustrado, por acontecimientos naturales, su destino), por lo cual el ordenamiento jurídico debe brindar la protección que ella se merece, teniendo presente la dignidad de trato que supone el concepto vida humana. ${ }^{14}$

Dos principales objeciones se plantean a esta posición: la primera, estrictamente biológica, obedece al hecho de que se presente como un solo instante lo que es un proceso. La segunda surge de la determinación de si el cigoto es o no es un ser humano. Es indudable que el cigoto contiene la esencia, la naturaleza de la raza humana; su dotación genética solo es compatible con la de cualquier individuo de la especie humana. Sin embargo, para algunos, aun reconociendo que el cigoto es material celular humano vivo y, por lo tanto, merece protección, ello no puede llevar a considerarlo como una especie de hombre en miniatura. ${ }^{15}$

12 Fernandez Sessareco, Carlos. Nuevas tendencias en el Derecho de las Personas. Op. cit., p. 67.

$13 \quad$ Ib., p. 68.

14 BIDART CAMPOS, Germán. Conferencia del 30 de agosto de 1996, posgrado de especialización en Bioética de la Universidad Nacional de Mar del Plata, citado por MESSINA DE Estrella GutierRez, Graciela. Bioderecho. Buenos Aires: Abeledo-Perrot, 1998. p. 34.

15 MARTINEZ, Stella Maris. Op. cit., p. 78. 


\section{b) Teoría de la anidación}

Esta teoría señala que la vida humana recién puede considerarse a partir del momento en que el embrión se fija en el útero de la mujer, es decir, cuando se anida en él; este es un fenómeno que recién culmina a los 14 días de la relación sexual, cuando se produce la unión del espermatozoide masculino con el óvulo femenino. De estudios realizados, se llega a la conclusión de que, de todos los preembriones (cigotos) que se generan, solo el $50 \%$ se adhieren al útero materno y se pierde el resto. Otras investigaciones han determinado que solo el $42 \%$ se implanta. Y otras señalan que las dos terceras partes de los óvulos fecundados se pierden antes de la implantación. Ello lleva a sostener a los partidarios de esta teoría que, mientras no se produzca el fenómeno de la anidación, la vida solo es una posibilidad, no una realidad concreta, que sí lo es cuando el cigoto se fija en el útero. En todo caso, aun reconociendo que se trata de posibilidades de vida, recién con la anidación es digno de protección el embrión.

Las idea predominante que se genera como consecuencia de la anidación es la individualización, que viene avalada con dos propiedades: la unicidad (ser único e irrepetible) y la unidad (ser una sola cosa). Como quiera que antes de los 14 días puede presentarse una serie de fenómenos que no se traduce en la individualización, ello no puede ser tomado en consideración en lo que se refiere a asumir que estamos frente a un ser humano ni mucho menos que haya que protegerlo. Recién, a partir de los 14 días, finalizada la etapa de la anidación, se puede tener la certeza no solo de la individualización, sino de la seguridad de su posterior desarrollo.

El destacado ginecólogo argentino Roberto Nicholson señalaba lo siguiente:

Un embrión tiene la capacidad de dividirse en dos o de sumarse en uno. Las dos cosas pueden suceder hasta que el embrión tiene un cierto tamaño, ese tamaño coincide con la primera semana de la implantación en la pared uterina. El embrión nada en la trompa — donde se fecunda — tres días, se implanta en la cavidad del útero al séptimo día y es a partir de allí cuando se determina si va a ser un individuo o se va a dividir para conformar dos gemelos. Desde ese momento es persona y se da entre los siete y catorce días $\left[\ldots . .{ }^{16}\right.$

Las principales objeciones que se hacen a esta teoría es el de confundir individualidad con indivisibilidad. Velayos-Santamaría señala:

16 Citado por Messina de Estrella Gutierrez, Graciela. Op. cit., p. 39. 
Al decir que un individuo humano no lo es si se puede dividir, se está confundiendo individualidad con indivisibilidad [...] En todo caso, siempre habrá una individualidad con una potencialidad de divisibilidad cada vez menor, lo que no invalida el que en todo momento, antes y después de una división con separación de células, se pueda hablar de individuo/ individuos. ${ }^{17}$

Como puede apreciarse, las técnicas de los métodos anticonceptivos, tan en boga en los tiempos actuales, está en función de la determinación del momento en que se inicia la vida. Si asumimos la teoría de la anidación, los métodos que impiden que los preembriones se aniden no serán abortivos; mas, si asumimos la teoría de la concepción, muchos métodos serán considerados abortivos y, por tanto, proscritos por la ley.

\section{c) Teoría de la formación del sistema nervioso central}

En los últimos años, ha surgido una nueva teoría que trata de darnos una explicación respecto al inicio de la vida humana; en esta teoría, hacen coincidir dicho inicio con la formación del sistema nervioso central, esto es, con la formación del cerebro. En ese instante, se inicia la traslación de la información genética al sistema nervioso central, lo que constituye una verdadera instancia diferenciadora.

«En este momento aparecen los rudimentos de lo que será la corteza cerebral por lo que recién con la presentación de la llamada línea primitiva o surco neural estaríamos frente a un ser viviente que, más allá de su composición genética, tiene una pauta selectiva específicamente humana». ${ }^{18} \mathrm{La}$ actividad eléctrica del cerebro recién se presenta al cabo de ocho semanas desde la fecundación, por lo que recién puede estimarse que se ha iniciado la vida humana.

Estimamos que dato importante para esta aseveración es el criterio adoptado, casi universalmente, en el sentido de que la muerte del ser humano se produce con el cese de la indicada función superior. En efecto, tratándose de la legislación peruana, el cese de la función cerebral fue adoptado como criterio de haberse producido la muerte de una persona cuando esta iba a ser sometida a la extracción de sus órganos o tejidos para efectos de trasplante. Posteriormente, y a partir de julio de 1997, con la Ley General de Salud, se adoptó el criterio de la muerte cerebral como válida para todos los efectos.

Fernández Sessarego cuestiona esta posición, señalando que

17 Citado por VARSI, Enrique. Op. cit., p. 101.

18 MARTINEZ, Stella Maris. Op. cit., p. 85. 
la afirmación que hace diferir la aparición de la vida humana hasta la producción de dicho fenómeno [se refiere a la formación del sistema nervioso central, el cerebro] carece de consistencia si es que, tal como lo hemos sostenido, la vida humana es un proceso continuo desde la fecundación, en que se da toda la información genética necesaria que lleva indefectiblemente a la formación del ser, hasta la muerte, salvo que se presenten alteraciones de cualquier índole que interfieran dicho proceso. ${ }^{19}$

Juan José Lacadena, jurista español, abundando en argumentos que cuestionan esta posición, señala:

El hecho de que el EEG (electroencefalograma) plano durante un cierto tiempo sea hoy día un criterio aceptado para dictaminar clínicamente la muerte de un individuo no es comparable en absoluto al EEG plano de un embrión en desarrollo: en el primer caso el cerebro ha dejado de funcionar [... en el segundo caso aún no ha empezado porque su programa genético de desarrollo todavía no ha mandado la información necesaria para ello. ${ }^{20}$

\section{El concebido como sujeto de derecho}

La única situación biológica y jurídica, real y concreta, es el concebido. Como señalamos, es el ser humano antes de su nacimiento, y nuestro sistema jurídico lo considera como sujeto de derecho; no es persona, pero sí es un centro de imputación de derechos y obligaciones. Está relacionado con el inicio de la vida del ser humano, sobre el que existen diferentes posiciones, que describiremos con detenimiento más adelante. Sin embargo, cualquiera que sea la posición que se asuma, lo cierto es que existe un período entre el inicio de la vida de un ser humano y su nacimiento. El ser humano que se encuentra en dicho período es considerado como sujeto de derecho.

¿Qué significado tiene el ser considerado como sujeto de derecho? En primer lugar, se le otorga una protección jurídica al ser humano que se encuentra en dicho período de su existencia, reconociendo su realidad biológica. Es un tratamiento directo, sin ficción de ninguna clase, convirtiéndolo en un ser con aptitud para adquirir derechos y obligaciones. No solo desde el punto de vista biológico es un ser distinto de la madre, sino desde el punto de vista jurídico es un sujeto de derecho distinto de la madre. En

19 Fernandez Sesarego, Carlos. Nuevas tendencias en el Derecho de las Personas. Op. cit., p. 68.

20 LaCADENA CALERO, Juan Ramón. "Manipulación genética de la especie humana». En Ingeniería genética y reproducción asistida. Madrid: Marino Barbero Santos, 1989, p. 28. 
consecuencia, cuando nos referimos al concebido, identificamos un sujeto de derecho tan igual que los demás sujetos de derecho aun cuando se trate de un sujeto privilegiado, como lo vamos a apreciar cuando veamos el tema de la percepción de los derechos, y aun cuando sea un ser dependiente biológicamente de la madre. ${ }^{21}$

¿Por qué no considerarlo como persona, como si lo ha hecho el Código Civil argentino, redactado por Vélez Sarfield? La opción de nuestro legislador ha sido respetar el concepto de persona, que es el ser humano a partir de su nacimiento con vida. Pero ¿cuál es la diferencia entre considerarlo como persona o solamente como sujeto de derecho? En realidad, la persona no tiene condicionamiento alguno para la percepción de los derechos; en cambio, tratándose del concebido, la percepción de los derechos patrimoniales está condicionada a que nazca con vida. Esta es una de las razones por las cuales es posible diferenciar al sujeto de derecho de la persona aun cuando, como ya hemos visto, toda persona es sujeto de derecho.

Esta es una de las ideas gravitantes en el pensamiento de Fernández Sessarego y convierte a nuestro Código Civil de 1984 en pionero en brindar un tratamiento directo al concebido que prescinde de la teoría de la ficción, que tanta fuerza ha tenido en el derecho occidental. En efecto, bajo su concepción, son cuatro los sujetos de derecho: el concebido, la persona natural, la persona jurídica y los denominados entes no personificados u organizaciones no inscritas. De esta forma, dicho Código Civil considera al concebido sujeto de derecho, sin asimilarlo al concepto de persona, que es el ser humano a partir de su nacimiento. En ese sentido, prescinde de la teoría de la ficción de considerar al concebido como nacido para protegerlo. ${ }^{22}$

El concebido no es ninguna ficción: es una realidad y como tal debe ser tratado por el derecho directamente, con las prerrogativas que se le conceden.

\section{La procreación humana. La inseminación artificial y la fecunda- ción extrauterina}

El tema de la procreación humana se ha perfilado por medio de dos expresiones: la inseminación artificial y la fecundación extrauterina. La primera consiste en lograr la fecundación sin cópula sexual cuando, por diversas

\footnotetext{
21 Fernandez Sessareco, Carlos. Nuevas tendencias en el Derecho de las Personas. Op. cit., p. 84.

22 Fernandez Sessareco, Carlos. Derechos de las Personas. Op. cit.; id. Nuevas Tendencias en el Derecho de las Personas. Op. cit.
} 
causas fisiológicas, tanto del hombre como de la mujer, no es posible lograr la fecundación. Si el problema es de la mujer, sea por trastornos endocrinos o del metabolismo, secreciones vaginales que neutralizan los espermatozoides, atresias vaginales que impiden la introducción adecuada del pene, se recurre al tratamiento terapéutico de la inseminación artificial con semen del marido; en buena cuenta, los elementos que originan la vida provienen de los esposos (inseminación homóloga). Mas, si el problema es por esterelidad del hombre (azzospermia, necrospermia, etc), la pareja puede decidir que se utilice el esperma fértil de un tercero. En este caso, estamos frente a la inseminación heteróloga, porque la fecundación se está obteniendo con un elemento aportado por una persona distinta a la pareja.

Los ejemplos descritos, indudablemente, no son los únicos, ya que existen múltiples posibilidades de combinaciones, conforme lo ha analizado Marcial Rubio. ${ }^{23}$ Para el tema que nos interesa determinar, debemos entender que la inseminación homóloga es aquella en la que los aportantes son los mismos esposos; y la heteróloga, en la que uno de los aportantes es un tercero, hombre o mujer. En el párrafo anterior, mencionamos como ejemplo el caso en que el problema lo tiene el hombre, pero puede ocurrir que el problema lo tenga la mujer; en esa circunstancia, el aporte será de otra mujer, entre cuyas posibilidades se encuentra el alquiler del vientre.

La fecundación extrauterina es aquella en la que la fecundación se logra, como su nombre lo indica, fuera del útero de la mujer. Se trata de la fecundación in vitro; en ella, también existe una gama de posibles combinaciones no solo en cuanto a los aportantes, sino además en cuanto a los consentimientos de las parejas. Nótese que, mientras en la inseminación artificial, la fecundación siempre será uterina, sea la esposa o una tercera persona, en la fecundación extrauterina, la fecundación se logra fuera del útero, independientemente de quiénes sean los aportantes de los elementos que originan la vida.

\section{Problemas éticos y jurídicos de la inseminación artificial}

Como lo hemos señalado en párrafos anteriores, es indispensable adoptar una posición en estos temas desde el punto de vista valorativo, axiológico, porque, si bien se trata de un método científico que permite dar una solución a los matrimonios infecundos, existe una serie de combinaciones posibles que ponen en tela de juicio esta metodología porque estas podrían resentir los sentimientos más apreciados por una colectividad que conduce

23 Rubio CORREA, Marcial. Las reglas del amor en probetas de laboratorio. Lima: Pontificia Universidad Católica del Perú, 1996. 
su existencia con determinados valores que los privilegia y, por ende, los protege.

Vamos a entrar a escudriñar los aspectos éticos y jurídicos de algunos temas específicos en los que, a nuestro criterio, se perfilan con mayor gravedad estos aspectos.

\section{a) Inseminación homóloga y heteróloga}

Hemos señalado que la inseminación homóloga se produce cuando los elementos que originan la vida son aportados por marido y mujer, mientras que la inseminación heteróloga se configura cuando uno de los elementos es aportado por un tercero. Es indudable que la inseminación homóloga es la que menos reparos éticos presenta actualmente y es la que menos problemas jurídicos ostenta. Sin embargo, no ha sido así siempre. Se ha tenido que esperar que el tiempo vaya consolidando la idea del beneficio. Recordemos que el Papa Pio XII, en el año 1951, sostenía:

El acto conyugal en su estructura natural, es una acción personal, una cooperación simultánea e inmediata de los cónyuges [...], mucho más que la unión de dos gérmenes que pueden también efectuarse artificialmente, es decir sin la acción natural de los cónyuges. El acto conyugal, ordenado y querido por la naturaleza, es una cooperación personal a la que los esposos, al contraer matrimonio, se otorgan mutuamente el derecho.

Posteriormente, en el II Congreso Mundial de la Fertilidad y Esterilidad, llevado a cabo el 19 de mayo de 1956, y más tarde en el VII Congreso de Hematología, del 12 de setiembre de 1958, en forma expresa señalaba: «La fecundación artificial viola la ley natural y es contraria al derecho y a la moral». ${ }^{24}$

Por nuestra parte, consideramos que, si bien lo natural es que la procreación de un ser humano se produzca como consecuencia de la relación sexual entre un hombre y una mujer y, más concretamente, por medio del coito, con la inseminación artificial homóloga, en la que los elementos que originan la vida son proporcionados por los propios cónyuges, no se desnaturaliza la procreación, ya que esta se producirá como consecuencia de la unión del espermatozoide masculino con el óvulo femenino y este fenómeno se producirá en el cuerpo de la mujer (cónyuge) intrauterinamente. El apoyo de la ciencia, en este sentido, es neutralizar los problemas orgánicos o fisiológicos, del hombre o de la mujer, que impiden que se genere la procreación de una manera normal.

24 ZaNNONI, Eduardo. Op. cit., pp. 45-46. 
Los reparos éticos se han ido diluyendo, porque no se desnaturaliza el acto de la procreación ni se desnaturaliza una de las finalidades del matrimonio, ya que se logra cumplir con el legítimo derecho de toda pareja conyugal de tener descendencia de su propia sangre.

Desde el punto de vista jurídico, la presunción pater is no se resiente, no se vulnera ni se pone en tela de juicio. Como son elementos biológicos proporcionados por los propios cónyuges y el tratamiento se ha hecho en el cuerpo de la mujer, para que ella sea la que logre la fecundación y el desarrollo posterior del concebido, la presunción funcionará plenamente.

Sin embargo, mencionaremos dos temas importantes relacionados con la inseminación homóloga:

a) Uno de ellos es si podemos aplicar las mismas reglas para las parejas estables no casadas, en las que, si bien formalmente no se aplicaría la presunción pater is, aun cuando somos partidarios de que extensivamente se aplique a este tipo de parejas, probablemente se encuentre algún tipo de reparos. Desde el punto de vista ético, no apreciamos diferencia respecto de la pareja casada, por cuanto se trata de una unión de hecho estable, similar a la de un matrimonio, solo que carece de las formalidades de este, pero es indudable que los sentimientos, las voluntades y las finalidades de dicha unión son semejantes a las matrimoniales. Por ello, nuestro sistema jurídico las regula, les concede un tratamiento especial y las protege, concediéndoles varios beneficios semejantes a las de una relación matrimonial.

La principal preocupación, en este aspecto, sería la aplicación de la presunción pater is, que, como hemos señalado, formalmente solo debería aplicarse a las relaciones matrimoniales. Somos partidarios de que se haga extensiva la aplicación de la presunción en comentario a las uniones de hecho. Una interpretación razonable, socialmente aceptable y justa de la norma que contiene la presunción pater is debería comprender extensivamente a las uniones de hecho. ${ }^{25}$

b) El otro tema que nos plantea problemas de orden ético y jurídico, en lo que se refiere a la inseminación homóloga, es la inseminación post mórtem. Se presentaría este caso cuando en vida pudo obtenerse el semen del esposo y ser conservado y luego este fallece. Luego del fallecimiento, se produce la intervención médica para practicar la inseminación artificial en el cuerpo de la esposa, de forma tal que se fecunda un nuevo ser. Obviamente, pueden existir algunas variantes como, por ejemplo, si el esposo dejó en vida expresa voluntad de que se lleven a cabo estas técnicas

25 En similares términos se expresa RUBIO CORREA, Marcial. Op. cit., p. 71. 
con su semen y con su esposa o, de forma contraria, si no es posible conocer dicha voluntad por no constar expresamente. Pero, independientemente de estas posibles variantes, ¿desde el punto de vista ético, son viables estas prácticas? Aquí, como en todos los problemas relacionados con el propio ser humano, se requiere de consensos sociales. Ponderar los beneficios y qué perjuicios de orden valorativo pueden generarse con estas prácticas es un ejercicio inevitable y urgente.

Marcial Rubio Correa se pronuncia en contra de esta posibilidad, señalando que la inseminación post mórtem, que hace que el niño nazca sin padre, quien es parte consustancial de la familia, debe ser prohibida por el derecho. ${ }^{26}$

De producirse un hecho de esta naturaleza, los conceptos tradicionales del derecho no nos ayudarían a solucionar el tema, por cuanto queda claro que, con el fallecimiento del esposo, se puso fin a dicha persona, ya no es más sujeto de derecho. Todos sus bienes, como sabemos, pasan a favor de sus herederos. Dejar de ser sujeto de derecho significa que no tiene la aptitud para adquirir derecho ni asumir obligaciones. No podría ser considerado como el padre de la criatura; así, nos encontraríamos con el contrasentido de que existiría un niño sin padre. No tendría padre. ¿Cuál sería la solución más razonable y socialmente aceptable? Esto nos plantea la necesidad de ser creativos para poder encontrar una solución valorativa y jurídicamente aceptable. ¿Permitir jurídicamente esa posibilidad? Nos pronunciamos a favor, con la mayor parte de los argumentos esgrimidos para aceptar la técnica entre parejas, cuyos integrantes está vivos, pero la necesidad de una regulación específica que prevea las distintas posibilidades y sus consecuencias sería imprescindible. Para ello, debería analizarse, en especial, el caso en que el padre difunto haya expresado su voluntad indubitablemente a favor de dicha práctica, para que se lleve a cabo después de su fallecimiento y dentro de un plazo razonable, que tendría que ser fijado por ley. ${ }^{27}$

\section{b) La presunción legal de paternidad}

Uno de los principios básicos que está presente y regula las relaciones matrimoniales, tanto en la legislación peruana como en la mayor parte de las

26 RUBIO CORREA, Marcial. Op. cit., p. 75. Las reconocidas juristas argentinas Dolores Loyarte y Adriana Rotonda también se pronuncian en contra de la procreación post mórtem en su libro Procreación humana artificial: un desafío bioético. Buenos Aires: Depalma, 1995, p. 334.

27 En términos semejantes se expresan Messina DE ESTRELLA GutierRez, Graciela. Op. cit., p. 136 y MORO AlMARAZ, Jesús. Aspectos civiles de la inseminación artificial y la fecundación in vitro. Barcelona: Bosch, 1988, p. 195. 
legislaciones latinoamericanas, es la presunción pater is. El artículo 361 lo recoge en los siguientes términos: «El hijo nacido durante el matrimonio o dentro de los trescientos días siguientes a su disolución tiene por padre al marido".

Evidentemente, estamos ante una presunción iuris tantum y no iure et de iure, ya que admite prueba en contrario. La presunción se basa en el hecho de que un matrimonio implica la cohabitación o relaciones sexuales entre los cónyuges, lo que, aunado con el compromiso de fidelidad entre ambos, hace que se presuma que el hijo nacido tenga como padre al marido. La consanguinidad se presume como garantía de la relación matrimonial, que es la base de la organización social, por lo que finalmente adquiere un carácter jurídico formal.

Lo que puede ocurrir en la experiencia jurídica es que el padre biológico sea efectivamente el marido, de tal suerte que no existirá discrepancia alguna entre la realidad biológica y la jurídica. Sin embargo, también puede ocurrir lo contrario, es decir, que el marido no sea el padre biológico, en cuyo caso está facultado para impugnar la paternidad; así, no será el padre por razones biológicas y jurídicas, en virtud de la declaración judicial que cuestiona la presunción pater is.

Sin embargo, el blindaje con que se dota a la presunción llega al punto de conceder facultades de impugnación solo al marido, de tal suerte que, si este no impugna la paternidad, a pesar de que biológicamente no es su hijo, será su hijo jurídicamente. El verdadero padre, el padre biológico, no podrá solicitar el reconocimiento de dicho hijo como suyo, si es que el marido no ha contestado la paternidad previamente y obtenido sentencia favorable. El artículo 396 del Código Civil señala taxativamente lo siguiente: «El hijo de mujer casada no puede ser reconocido sino después de que el marido lo hubiese negado y obtenido sentencia favorable». En concordancia con el numeral mencionado, tenemos el artículo 404 del mismo cuerpo de leyes, que señala: «Si la madre estaba casada en la época de la concepción, sólo puede admitirse la acción en caso que el marido hubiera contestado su paternidad y obtenido sentencia favorable».

Observamos que la presunción en comentario se convierte en un verdadero bastión de protección de las relaciones familiares y, especialmente, en lo que se refiere a los hijos habidos dentro de ella, por lo que corresponde referirnos a lo que ocurriría con ella en los casos de inseminación artificial.

En lo que se refiere a la inseminación homóloga, en la que, como hemos señalado, los elementos que originan la vida son aportados por los mismos cónyuges, no se perciben problemas con la presunción, porque existirá una coincidencia entre el padre biológico con el padre jurídico. En esta relación no existe la presencia de ningún elemento extraño a la propia pareja. Se 
trata de sus propios elementos y lo que hace la ciencia es facilitar la procreación y consecuente desarrollo del nuevo ser. La presunción pater is, sencillamente, confirmará lo que es una realidad, es decir, que el hijo ha sido procreado por la madre, como consecuencia del aporte de los elementos, tanto de ella como del marido. Lo genético y lo jurídico coincidirán.

No podemos afirmar lo mismo respecto de la inseminación heteróloga, en la que existe la presencia de uno de los elementos que originan la vida aportados por un tercero, obviamente, extraño a la relación matrimonial. En lo que se refiere a la presunción, el aporte tendría que provenir de un hombre, distinto del marido. En estos casos, ¿funciona la presunción pater $i s$ ? Independientemente de que consideremos que para estos temas es indispensable una regulación legislativa, qué ocurre si se lleva a cabo una inseminación heteróloga. Creemos que también funciona la presunción pater is, pero con la atingencia de que el marido no podrá contestar la paternidad si consintió en la práctica de la inseminación.

Indudablemente, tenemos que distinguir dos situaciones: una, en la que el marido consiente en la práctica de la inseminación, está de acuerdo; y la otra, en la que se ha llevado a cabo sin su consentimiento o con su total desconocimiento. En la primera situación, es evidente que funcionará la presunción pater is; el tercero aportante no podrá solicitar el reconocimiento del hijo si el marido no impugna la paternidad. Pero, además, el marido no podrá contestar la paternidad, en razón de haber prestado su consentimiento en la práctica de dichas técnicas, pese a que no es su hijo genéticamente hablando. Existen razones de orden ético que nos llevarían a esta última solución, pero también razones de orden jurídico, si se aplica la doctrina de los actos propios. En efecto, ni jurídica ni éticamente se puede obtener un beneficio sobre la base de un acto propio, el cual lo estaría contradiciendo para lograr un determinado objetivo favorable para él, pero perjudicial para otros. Luego de haber prestado su consentimiento, sería una conducta absolutamente desleal si, posteriormente, contradijera dicho acto, emanado como expresión de su voluntad, colocando a la otra persona en una situación desventajosa solo con la finalidad de lograr un provecho. Es legítimo suponer que la mujer procedió a la práctica de la inseminación heteróloga, porque el marido consintió, ya que de lo contrario no lo hubiera hecho.

En la segunda situación, también funcionará la presunción pater is, toda vez que ha sido un hijo habido dentro de la relación matrimonial, pero no existirá la limitación respecto del derecho del marido de impugnar la paternidad, en razón de no ser el padre biológico, como ocurre en el caso anterior. El tercero aportante, en ese sentido, no podrá solicitar el reconocimiento del hijo, mientras que el marido no haya contestado la paternidad y 
haya obtenido una sentencia favorable. De lo que se desprende, también, que, si el marido no toma ninguna determinación, él será considerado como padre del hijo habido por su mujer. En buena cuenta, funciona la presunción pater is exactamente en los mismos términos propuestos por el Código Civil.

\section{c) Reclamo de la paternidad por el dador del semen}

Este es un supuesto, a todas luces, extraño, máxime si entendemos que los aportantes deberían estar en la situación de anónimos. No obstante, debemos asumirlo como una posibilidad. ¿Una regulación legislativa sobre el tema podría considerar esta posibilidad? ¿Acaso no es mejor cerrar cualquier posibilidad al respecto, a fin de mantener la unidad familiar? El tercero que entregó su semen lo hace con plena conciencia de que se utilizará para solucionar un problema de infertilidad matrimonial, por lo que no tiene ni en su conciencia ni en su voluntad el considerarse como futuro padre, aun cuando genéticamente sí lo sea.

El primer y principal escollo será la presunción pater is, ya que el reconocimiento del hijo por parte del tercero aportante estará sujeto a que previamente el marido haya contestado la paternidad judicialmente y obtenido sentencia favorable. Solo en este último supuesto podría admitirse la posibilidad del reconocimiento por parte del tercero, ya que también sería inaceptable que el hijo habido por la mujer, cuya paternidad ha sido impugnada por el marido, se quede sin padre.

El solo argumento de que se trata de su hijo genéticamente hablando no será suficiente para el reclamo de la paternidad por razones de orden ético y jurídico. Tendría que superar el blindaje que otorga la presunción pater is y la única forma queda a discreción del marido. Si el marido no cuestiona la paternidad, él será el padre jurídicamente hablando y el tercero aportante no tendrá la menor posibilidad de que se le reconozca como padre.

\section{d) La maternidad subrogada (alquiler de vientre)}

Tema de singular importancia por los diversos problemas de orden jurídico que pudiera generar, no sin dejar de lado el tema ético que entraña, es el relativo a la denominada maternidad subrogada. Nuestro sistema jurídico no la admite: existe una prohibición tácita en la Ley General de Salud, que coincide con la posición de la Iglesia católica; en el artículo siete de esta ley, se establece que la condición de madre genética debe coincidir con la de madre gestante. 
En el Perú, tanto Varsi ${ }^{28}$ como Rubio Correa, ${ }^{29}$ se han pronunciado en contra, pero demuestran su preocupación en los casos en que ocurra, pese a la tácita prohibición legal.

Existe una gama de variantes en las combinaciones de los elementos que originan la vida: desde el caso extremo en el cual la madre subrogada aporta el óvulo que es fecundado por los espermatozoides de su marido, pero el embarazo se desarrolla en el vientre de otra mujer, que aporta solo su cavidad uterina, hasta el otro extremo, en el que ni la madre subrogada ni su marido aportan los elementos que originan la vida, pero contratan los servicios de una tercera persona (mujer) para que el embarazo se desarrolle en su cavidad uterina con una embrión logrado con el aporte de terceros.

Pongámonos en la primera situación. En el supuesto que ocurra, pese a la expresa prohibición antes señalada, el principio de que la madre siempre es cierta tendrá que primar, de tal suerte que la madre será aquella que alumbra al niño. El acto jurídico que pudiera haberse celebrado entre las partes, madre subrogante y madre subrogada, sería contrario al orden público, por lo que padecería de ineficacia y, más concretamente, de ineficacia estructural, puesto que sería un acto jurídico nulo. Como lo señala Rubio, «es conveniente que en la sociedad se establezca que el principio de la madre siempre es cierta tiene validez universal como regla de la organización de las relaciones sociales». ${ }^{30} \mathrm{El}$ principio debe imponerse pese a que, genéticamente, la madre es la que aportó el óvulo y el padre es el marido que aportó el esperma. Sin embargo, la gestante y que alumbró, pese a no haber aportado genéticamente ningún elemento, sería considerada la madre jurídicamente. Evidentemente, dentro de este supuesto, debe tenerse en consideración si la madre subrogante es soltera o casada. Si es soltera, para ser coherentes, debemos concluir defendiendo el principio de que la madre siempre es cierta. La subrogante será la madre y el padre será el marido de la subrogada, ya que no podemos admitir que el niño no tenga padre. Si se trata de una mujer casada, no solo debe aplicarse el principio antes aludido, sino, además, la presunción pater is. La que alumbró al niño será la madre (subrogante) jurídicamente y el padre será su marido, en virtud de la presunción pater is, con las consecuencias que de ello deriva.

Entre los dos extremos que hemos mencionado, existe una serie de combinaciones:

\footnotetext{
28 VARSI, Enrique. Op. cit., p. 263.

29 Rubio CORREA, Marcial. Op. cit., p. 124.

$30 \quad$ Ib., p. 126.
} 
- si el óvulo es aportado por la madre subrogada, pero el esperma pertenece a una persona distinta del marido y el embarazo se desarrolla en la cavidad uterina de la subrogante, con conocimiento del marido;

- si el óvulo es aportado por persona distinta a la cónyuge, pero el esperma pertenece al marido y el embarazo se desarrolla en la cavidad uterina de la subrogante, con conocimiento de la cónyuge;

- si el óvulo es aportado por la cónyuge subrogada, pero el marido no es el aportante del elemento que origina la vida, ya que él mismo proviene de una tercera persona, y desconoce el acuerdo o no presta su consentimiente en el convenio que se celebra con la madre subrogante;

- si el óvulo es aportado por persona distinta a la cónyuge, pero el esperma pertenece al marido y el embarazo se desarrolla en la cavidad uterina de la subrogante sin consentimiento ni conocimiento de la cónyuge; o

- si la madre subrogante es casada, no aporta el elemento femenino y, en el convenio que celebra con la pareja subrogada, no interviene su cónyuge, quien desconoce el acuerdo o no presta su consentimiento.

Como podemos observar, en el supuesto de admitir la maternidad subrogada en cualquiera de las situaciones descritas, que no son las únicas, estaríamos frente a una donación de hijos o en verdaderos casos de venta de hijos.

Pese a que nuestra posición en este tema es coincidente con lo establecido en la Ley General de Salud, no deja de motivar inquietudes la posición asumida por algunos juristas que argumentan, justificando ética y jurídicamente, que el sistema jurídico viabilice la maternidad subrogada como una solución a un problema de orden existencial, para unos, y solución de un problema económico, para otros, vía una relación contractual. ${ }^{31}$ En ese sentido, el intercambio y debate de las ideas continúa abierto.

\section{Problemas jurídicos de la fecundación extrauterina}

Al igual que ocurre con la inseminación artificial, la fecundación extrauterina nos plantea una serie de problemas de orden ético y jurídico. Lo ocurri-

\footnotetext{
BULLARD, Alfredo. "¿Qué puede ser objeto de un contrato?. El alquiler de vientre y las madres sustitutas». En Derecho y Economía. Lima: Palestra, 2003, pp. 198-223. Señala el autor, como conclusión de su posición: "La capacidad reproductiva humana es, a pesar de la tecnología, un recurso relativamente escaso en cuanto muchas personas, que con el legítimo interés de tener hijos, han sido privadas biológicamente de tal posibilidad. Y nadie puede dudar que la experiencia de ser padre o madre es uno de los más hermosos canales para conseguir la realización humana. No dejar que la capacidad reproductiva pueda ser puesta al servicio de dicha realización, no sólo puede ser económicamente ineficiente, sino incluso humanamente injusto» (p. 223).
} 
do con Louse Brown, en julio de 1978, fue un hito trascendental en el avance de la ciencia biológica. Conseguir la fecundación fuera de la cavidad uterina, logrando unir el óvulo femenino con el espermatozoide masculino, significó, a la vez que la culminación de una serie de experiencias en el campo de la biología, el comienzo de nuevas etapas, cualitativamente diferentes de las anteriores, en el campo del conocimiento y la investigación científica. Como se trata de un tema cualitativamente diferente, los conceptos e instituciones jurídicas tradicionales se ponen en tela de juicio. En ese sentido, la creatividad, la imaginación resultan ser la prioridad en el campo jurídico, obviamente cotejadas siempre con los valores imperantes en la colectividad y lo que universalmente se ha logrado como consenso.

La investigación sobre embriones humanos in vitro ha provocado posiciones divergentes desde el punto de vista ético, filosófico, religioso y de tradiciones nacionales. En la legislación europea, se observan las discrepancias en temas como los siguientes: la regulación legal o no de la investigación sobre embriones humanos; la prohibición de investigar sobre embriones directa o indirectamente; la limitación de la disponibilidad de los embriones para la investigación; la prohibición o limitación de la creación de embriones sobrantes; la prohibición o limitación de la críoconservación de embriones sobrantes; la prohibición de otros sistemas de obtención de embriones para la investigación; la limitación de la fase de vida embrionaria; el uso de embriones después de la investigación; la supervisión de los proyectos de investigación que supongan la experimentación con ovocitos humanos fertilizados, fetos y embriones. ${ }^{32}$

Sin embargo, pese a las discrepancias, existen valores comunes aceptados por la comunidad europea, que merecen ser relievados:

a) el respeto a la vida humana desde el estado embrionario,

b) la necesidad de paliar el sufrimiento humano,

c) la necesidad de prestar garantías de calidad y la seguridad en los tratamiento médicos,

d) el principio de libertad de investigación y

e) la exigencia del consentimiento libre e informado de las mujeres y de las parejas comprometidas. ${ }^{33}$

Nos referiremos solo a algunos de los temas con implicancias jurídicas más preocupantes.

\footnotetext{
32 BERGEL, Salvador Darío. Op. cit., p. 63.

33 Ib., p. 64.
} 


\section{a) ¿El comienzo de la subjetividad o de la personalidad?}

Nuestro sistema jurídico resulta original en el mundo en lo que se refiere al tratamiento del concebido, ya que l,o considera como sujeto de derecho y le otorga un tratamiento directo, prescindiendo de la teoría de la ficción, que lo consideraba como nacido para poder protegerlo. En consecuencia, el Código Civil de 1984 considera al concebido como uno de los sujetos de derecho, mas no como persona, que es el ser humano a partir de su nacimiento con vida.

Sin embargo, esta posición clara del Código Civil es contradicha tácitamente por el Código de los Niños y Adolescentes cuando considera que el niño lo es desde el momento de la concepción. Como se trata de una norma de la misma jerarquía y ha sido dictada con posterioridad, se ha producido una derogación tácita al existir incompatibilidad entre la nueva disposición y la antigua. En ese sentido, se asemejaría a la posición del Código Civil argentino que, como sabemos, considera que persona es el ser humano desde el instante de la concepción y no solo desde el nacimiento. El concebido, para la legislación argentina y para el Código de los Niños y Adolescentes, sería persona, obviamente, sujeto de derecho. ${ }^{34}$

¿La fecundación extrauterina, en la que la concepción se produce fuera del claustro materno, en probeta, para luego, una vez formado el embrión, o el preembrión como algunos prefieren, introducirlo en el útero de la mujer, nos plantea alguna variante en la concepción? Recordemos que la idea de la concepción ha supuesto siempre que la misma se produce intrauterinamente. ¿Desde qué momento podemos considerar que comienza la personalidad o la subjetividad?, que es lo mismo que preguntar ¿¿desde qué momento podemos considerar que comienza la vida humana?

Para responder a esta pregunta existen las tres teorías que hemos expuesto líneas arriba, sobre las que no vamos a insistir. En todo caso, hay que señalar que nuestra legislación ha optado por la teoría de la concepción, es decir, cuando se unen el óvulo femenino con el espermatozoide masculino, lo que genera el cigoto. En el caso de la fecundación extrauterina, lo que ocurre es la formación de varios y, luego, se escoge uno para que continúe su desarrollo, pero ¿̇y los demás? Es indudable que debemos ser coherentes. Estamos en presencia de vida humana no solo del que se inocula en el útero

34 Este es un tema ampliamente debatido en la doctrina, en el que se agudizan las dificultades con el tema de la fecundación extrauterina. Diez Picazo estaba convencido de que la personalidad debe ir ligada a la existencia de vida humana; sin embargo, era consciente de la tradición de reservar la noción de persona al ser humano desde su nacimiento. (Citado por MORO Almaraz, Jesús. Op. cit., p. 134). 
de la mujer, sino de todos, por lo que es importante determinar qué es lo se va a hacer con ellos. ¿Se conservarán?, ¿los harán desaparecer?

En todo caso, la interrogante continúa en el sentido de si estamos frente a un ser humano desde el instante de la concepción, aun cuando esta se haya producido extrauterinamente, o recién vamos a considerarlo como tal cuando se implante en la cavidad uterina. Creemos, por nuestra parte, guardando coherencia, que estamos frente a un ser humano desde el instante de la concepción. ${ }^{35}$

\section{b) El delito de aborto}

Relacionado con lo expresado anteriormente, tenemos el tema del aborto. En efecto, si se prescinde o se hacen desaparecer los embriones ya formados, luego de haber escogido uno de ellos, estamos frente a la interrupción de un proceso de vida que ya comenzó con la concepción. ¿Es aborto? Pero resulta que la concepción tradicional del aborto implica la interrupción del proceso de embarazo, es decir, del desarrollo de la vida humana intrauterinamente. Como no funciona la analogía en el derecho penal, no podrían comprenderse como aborto, bajo el tipo señalado anteriormente, las interrupciones del proceso de desarrollo de los embriones formados extrauterinamente, in vitro. ¿ No es un criterio desigualitario el sancionar penalmente la interrupción del desarrollo de la vida humana intrauterinamente y dejar impune el mismo hecho, pero respecto de embriones formados en probetas, in vitro?

Evidentemente, es imprescindible guardar coherencia respecto del inicio de la vida, porque ello nos llevará de la mano para solucionar muchos temas, entre ellos el que comentamos. Si es así, deberíamos ampliar el contenido del tipo penal del aborto o, en todo caso, generar un tipo específico que proteja dicha situación.

\footnotetext{
«El proceso es el mismo, se haya concebido fuera o dentro del útero materno. El que se encuentra fuera está más expuesto a su deterioro. [...] Su mayor fragilidad no ha de condicionar una desatención total, sino todo lo contrario. [...] Si no lo asimilamos al nasciturus la protección sería casi nula, la de éste es ya mucho más recortada que la de la persona. Al menos, debe recibir el mismo trato. Y si afirmamos que son realidades distintas, habría que llegar a la conclusión también de que los seres nacidos de mujer tras fecundación natural o artificial no son equiparables. [...] La tutela debe ser al embrión vivo cualquiera que sea su ubicación, los aspectos concretos vendrán regulados por normas específicas, pero mientras éstas no se establezcan la del nasciturus le alcanzará en los mismos términos». (Ib., pp. 130-131).
} 


\section{c) Selección eugenésica}

Siempre han existido ideas relacionadas con el mejoramiento de la especie humana, como también siempre han existido ideas sobre la superioridad de determinado tipo de ser humano. ${ }^{36}$ Con la manipulación de los elementos que originan la vida, no puede ser ajeno el interés de pretender efectuar combinaciones selectivas con la mira de lograr «una mejor conformación humana». La selección eugenésica es reprochable porque desvirtúa totalmente la naturaleza ética de la procreación, salvo que se utilice con fines terapéuticos que intenten prevenir taras hereditarias.

El problema no solo son las posibles combinaciones selectivas, sino las alteraciones que pudieran ocasionarse de la naturaleza del ser humano. Si se han logrado mutaciones en el campo de la zoología y la botánica, como consecuencia de buscar mejores especies, por su belleza, por su producción o por simple experimentación, nada nos impide pensar que ello no pueda ocurrir con el ser humano.

36 JUNQUERA DE ESTEFANI, Rafael. Reproducción asistida, filosofía ética y filosofía jurídica. Madrid: Tecnos, 1998, pp. 148-149. 